
\title{
3 Research Square \\ Factors Influencing Survival Time in Patients Treated for Oesophageal Cancer with Palliative Intent in South Africa
}

Lucien Ferndale ( $\square$ lucienferndale@gmail.com )

Grey's Hospital

Oluwatosin A Ayeni

University of the Witwatersrand

Wenlong Carl Chen

National Health Laboratory Service

Colleen Aldous

University of KwaZulu-Natal

\section{Research Article}

Keywords: Keywords Oesophageal cancer, survival, Africa

Posted Date: November 19th, 2021

DOI: https://doi.org/10.21203/rs.3.rs-1074694/v1

License: (9) This work is licensed under a Creative Commons Attribution 4.0 International License. Read Full License 


\section{Abstract}

\section{Background}

Most patients presenting with oesophageal cancer to South African institutions present late with advanced disease and are eligible for palliative treatment only. The optimal management of these patients is dependent on their expected survival but factors affecting survival in our setting is unknown.

\section{Methods}

We assessed factors influencing survival in patients diagnosed with oesophageal squamous cell carcinoma at Grey's hospital in KwaZulu-Natal, South Africa. Factors assessed for effect on prognosis included patient demographics, clinical and laboratory data and tumour factors. Patients were divided into two groups; those that survived for less than or equal to three months and those that survived for more than three months.

Univariate and multivariate analyses were performed to determine which factors significantly influenced whether patients survived for more than three months or not.

\section{Results}

A total of 384 patients were entered into the study. There were 218 males with a female to male ratio of 1:1.3. The median survival of the cohort was 3.7 months. One hundred and sixty-one (41.9\%) patients survived three months or less, while $223(58.1 \%)$ of patients survived more than three months. Factors that influenced survival on univariate and multivariate analysis were the area of residence, body mass index, serum albumin and performance status.

\section{Conclusion}

Area of residence, body mass index, serum albumin and performance status significantly affect survival in patients treated palliatively for advanced oesophageal cancer at our institution. This knowledge can be used to plan the optimal management algorithm for these patients.

\section{Introduction}

The prognosis of oesophageal cancer is known to be poor. ${ }^{[1]}$ Most patients are diagnosed at an advanced stage and are therefore eligible for palliative management only. ${ }^{22]}$ Survival beyond a few months in this group of patients is rare. ${ }^{[3]}$ The two main histological subtypes are squamous cell carcinoma and adenocarcinoma. Oesophageal squamous cell carcinoma (OSCC) is endemic in South Africa, with certain parts of the country making up part of the African oesophageal cancer corridor. ${ }^{[4]}$

Adequate management of patients with OSCC in South Africa is challenging, with many centres being inadequately equipped to provide patients with adequate care. The vast majority of patients require 
palliative care only, owing to the advanced stage of the disease at the time of presentation. There are,

however, no clear guidelines on the selection of patients for different management options. ${ }^{[5,6]}$

Clinicians need to know how to select patients for palliative or curative management soon after presentation. This will help optimise care and avoid subjecting these already ill patients to unnecessary investigations that are unlikely to impact their prognosis or improve their quality of life.

This study aimed to assess factors that influenced survival time in patients with oesophageal cancer that received palliative management. We plan to use the significant factors to develop and validate a prognostic score that would aid clinicians in decision-making when seeing patients with oesophageal cancer.

\section{Methods}

\section{Study setting}

All patients with histologically confirmed OSCC presenting to Grey's hospital between April 2016 and November 2020 were electronically entered into an oesophageal cancer database. Grey's hospital is a tertiary hospital located in Pietermaritzburg, KwaZulu-Natal, the second-most populous province in South Africa. ${ }^{[7]}$ Its catchment area has approximately three million people, of whom two-thirds are from rural areas. The hospital provides a variety of oncology services, including diagnostic services, surgery, chemotherapy and radiation therapy. ${ }^{[8,9]}$

For this analysis, we included all adult patients with a confirmed diagnosis of OSCC, those treated palliatively, and those with whom the date of death or last follow-up status was known. We excluded patients receiving treatments for curative intent and those that were lost to follow-up with no known date of death. The study was approved by the Biomedical Research Ethics Committee of the University of KwaZulu-Natal (UKZN), Durban, South Africa (Certificate number BF270/15).

\section{Data collection and processing}

Data on socio-demographics, behavioural factors, anthropometric measures, clinical presentation, laboratory results and treatment were collected at diagnosis.

Factors known to influence survival in advanced oesophageal cancer were assessed. These include age and gender, ${ }^{[10]}$ Body mass index (BMI), ${ }^{[11]}$ geographic area, ${ }^{[12]}$ smoking, dysphagia score, serum albumin, performance status, ${ }^{[13-15]}$ tumour location, length ${ }^{[16]}$ and differentiation. ${ }^{[17]}$ In addition, we assessed the effects of HIV status, alcohol use, and race on survival.

Bodyweight and height were measured at diagnosis, and patients were categorised as underweight (BMI $\leq 18.5 \mathrm{~kg} / \mathrm{m} 2)$ or not underweight $(\mathrm{BM}>18.5 \mathrm{~kg} / \mathrm{m} 2)$. ${ }^{[18]}$ Dysphagia score was graded according to the 
Mellow and Pinkas score. ${ }^{[19]}$ We assessed performance status using the Eastern Cooperative Oncology Group score. ${ }^{[20]}$ Tumour length was defined as the maximum length based on the diagnostic endoscopy, and tumour pathology was defined as well, moderate or poorly differentiated according to standard pathological guidelines. ${ }^{[21,22]}$ Albumin was categorised as severe hypoalbuminaemia (Serum albumin $<25 \mathrm{~g} / \mathrm{L}$ ) or serum albumin of at least $25 \mathrm{~g} / \mathrm{L}$, the level thought to be clinically significant. [23] When considering the area of residence, we differentiated between patients living within the Pietermaritzburg metropolitan area and those outside the metropole, which is mostly rural. [24]

\section{Description of palliative treatment}

Stent \pm dilatation without oncological therapy remains the primary treatment modality for a patient treated for OSCC with palliative intent. Dilatation is performed if needed at initial diagnostic endoscopy before histological confirmation or at the time of stent insertion to fully ascertain the distal extent of the tumour in order to select the correct stent.

Oncological treatment included external beam radiation therapy, chemotherapy or a combination of the two. The choice of oncological therapy was at the oncologist's discretion and dependent on the availability of resources.

Other treatments available were dilation only and/or best supportive care. Patients who received dilatation only were those in whom the tumour location precluded stent placement, e.g. very proximal tumours. Those who received the best supportive care were patients in whom the tumour could not be traversed endoscopically despite the added benefit of fluoroscopy and who were deemed too frail for oncological modalities based on performance status assessment.

\section{Outcome variable}

The date of death of patients was obtained from the patient's medical record or from publicly available administrative data, which uses data from the Department of Home affairs. Participants were grouped and analysed based on their survival time in months from date of accrual to date of death or date last known to be alive. Patients were divided into two groups; those that survived for less than or equal to three months and those that survived for more than three months. Patients that were alive after three months from diagnosis but were lost to follow-up thereafter were grouped in the $>3$ months category. We compared variables between the two groups to determine which factors affect survival time in patients treated palliatively for OSCC.

\section{Statistical analysis}


We compared the distribution of variables by survival time, using Mean \pm standard deviation (SD) for continuous variable age and Pearson's chi-squared test or Fisher's Exact test as appropriate for categorical variables. We then developed a multivariable logistic regression model to assess factors associated with survival time. We included in the multivariate model's variables for which $p$ values were $<0.1$ in univariate analysis and adjusted for each covariate and age reporting adjusted odds ratio (aOR) with $95 \%$ confidence interval $(\mathrm{Cl})$. Finally, we constructed Kaplan-Meier survival curve to assess overall survival in the cohort. All statistical analyses were performed using Stata version 16 (StataCorp Ltd, College Station, TX).

\section{Results}

Between April 2016 and November 2020, 468 patients were seen at the surgical clinic for OSCC, of which $435(93 \%)$ were offered palliative treatment. Of these, 51 (11.7\%) patients with unknown date of death or follow up were excluded leaving 384 patients for the final analysis. Overall, the mean age \pm SD at diagnosis was $61.8 \pm 11.2$ years. There were 218 (56.8\%) males with a female to male ratio of $1: 1.3$, and more than $95 \%$ of patients were of black African descent. The majority $(73.0 \%)$ of patients were from outside Pietermaritzburg metropolitan residential area (Table 1).

\section{Table 1}

\section{Demographic characteristics of patient cohort}




\begin{tabular}{|c|c|}
\hline Characteristics & Total, $\mathrm{N}=384(\%)$ \\
\hline Age in years, mean $\pm S D$ & $61.8 \pm 11.2$ \\
\hline \multicolumn{2}{|l|}{ Age group in years } \\
\hline$<70$ & $297(77.3)$ \\
\hline$\geq 70$ & $87(22.7)$ \\
\hline \multicolumn{2}{|l|}{ Gender } \\
\hline Male & $218(56.8)$ \\
\hline Female & $166(43.2)$ \\
\hline \multicolumn{2}{|l|}{ Race } \\
\hline Asian & $9(2.3)$ \\
\hline Black African & $368(95.8)$ \\
\hline Mixed race & $5(1.3)$ \\
\hline White & $2(0.5)$ \\
\hline \multicolumn{2}{|l|}{ Residential area } \\
\hline Pietermaritzburg metropolitan & $103(27.0)$ \\
\hline Other & $279(73.0)$ \\
\hline \multicolumn{2}{|l|}{ Home language } \\
\hline Zulu & $337(87.8)$ \\
\hline Others & $47(12.2)$ \\
\hline \multicolumn{2}{|l|}{ Referral centre } \\
\hline District & $118(32.1)$ \\
\hline Regional & $241(65.5)$ \\
\hline Outside drainage area + private & $9(2.4)$ \\
\hline \multicolumn{2}{|l|}{ Smoker } \\
\hline Present or past & $177(49.4)$ \\
\hline Never & $181(50.6)$ \\
\hline \multicolumn{2}{|l|}{ Alcohol } \\
\hline Present or past & $170(47.6)$ \\
\hline Never & $187(52.4)$ \\
\hline
\end{tabular}




\begin{tabular}{|lc|}
\hline Traditional beer use & \\
\hline Present or past & $2144(40.4)$ \\
\hline Never & $219.6)$ \\
\hline Missing data: Referral centre $(n=16)$, smoker $(n=26)$, alcohol $(n=27)$, traditional bear use $(n=28)$ \\
\hline
\end{tabular}

A quarter of the patients were HIV infected. Most tumours were located in the mid-oesophagus (55.7\%) and moderately differentiated (82.8\%). Overall, $343(89.4 \%)$ of the patients had stent \pm dilatation as a method of palliative management, 27 (7.0\%) had dilatation \pm best supportive care, and 14 (3.6\%) had oncological treatment only. The median survival of all patients receiving palliative treatment was 3.7 months. The overall survival was $58.1 \%$ at three months, $30.3 \%$ at six months and $9.8 \%$ at 12 months (Figure 1 and Table 2).

\section{Table 2}

Clinical Characteristics of patient cohort 


\section{Characteristics}

Total, $\mathrm{N}=\mathbf{3 8 4}(\%)$

Body Mass Index (BMI)

Underweight

$172(49)$

Not underweight

$179(51)$

\section{HIV status}

Negative

$237(74.5)$

Positive

$81(25.5)$

Albumin

$<30 \mathrm{~g} / \mathrm{L}$

$145(41.2)$

$\geq 30 \mathrm{~g} / \mathrm{L}$

$207(58.8)$

Albumin

$<25 \mathrm{~g} / \mathrm{L}$

57 (16.2)

$\geq 25 \mathrm{~g} / \mathrm{L}$

\section{Dysphagia grade (At presentation)}

0 - 1

83 (21.7)

$2-4$

$299(78.3)$

\section{Tumour location from incisors}

Proximal oesophagus

71 (19.2)

Mid oesophagus

206 (55.7)

Distal oesophagus

$93(25.1)$

Tumour length

$<8 \mathrm{~cm}$

225 (58.9)

$\geq 8 \mathrm{~cm}$

$157(41.1)$

Histology of the tumour

Well-differentiated

$18(5.4)$

Moderately differentiated

275 (82.8)

Poorly differentiated

39 (11.7)

${ }^{\text {a }}$ ECOG

0-1 


\section{Method of Palliation}

Dilate only + /- best supportive care

Oncological therapy

Stent + /- dilate without oncological therapy

Overall survival in months, median (IQR)
$27(7.0)$

14 (3.6)

$343(89.4)$

$3.7(1.6-6.7)$

Abbreviation: ${ }^{a}$ ECOG (Eastern Cooperative Oncology Group). IQR = Interquartile range. Missing data: BMI $(n=33)$, HIV $(n=66)$, albumin $(n=32)$, dysphagia $(n=2)$, tumour location $(n=14)$, tumour length $(n=2)$, histology $(n=52)$, ECOG $(n=12)$.

Compared to patients that survived for less than or equal to three months, patients who survived longer than three months were more likely to reside in the Pietermaritzburg urban metropolitan area $(p=0.033)$, more likely not to be underweight $(p<0.001)$, more likely to have albumin of $\geq 25 \mathrm{~g} / \mathrm{L}(\mathrm{p}<0.001)$, more likely to present with dysphagia grade of $0-1(p=0.033)$, more likely to have a tumour length of $<8 \mathrm{~cm}(62.6 \% \mathrm{vs}$ $53.8 \%, p=0.082)$ and more likely to have a performance status of $0-1(p<0.001)($ Table 3$)$.

Table 3

Univariate analysis of factors associated with survival time $>3$ months 


\begin{tabular}{|c|c|c|c|c|}
\hline \multicolumn{5}{|c|}{ Survival in months } \\
\hline & $\leq 3$ months & $>3$ months & $\begin{array}{l}\text { Univariate } \\
\text { analysis }\end{array}$ & P-value \\
\hline Survival time (row \%) & $\begin{array}{l}161 \\
(41.9 \%)\end{array}$ & $\begin{array}{l}223 \\
(58.1 \%)\end{array}$ & OR $(95 \% \mathrm{Cl})$ & \\
\hline \multicolumn{5}{|l|}{ Age group in years } \\
\hline$<70$ & $120(74.5)$ & $177(79.4)$ & $1.31(0.81-2.13)$ & 0.264 \\
\hline$\geq 70$ & $41(25.5)$ & $46(20.6)$ & 1.00 (Ref) & \\
\hline \multicolumn{5}{|l|}{ Gender } \\
\hline Male & $99(61.5)$ & $119(53.4)$ & 1.00 (Ref) & 0.113 \\
\hline Female & $62(38.5)$ & $104(46.6)$ & $1.40(0.92-2.11)$ & \\
\hline \multicolumn{5}{|l|}{ Race } \\
\hline Black African & $158(98.1)$ & $210(94.2)$ & 1.00 (Ref) & 0.069 \\
\hline Others & $3(1.9)$ & $13(5.8)$ & $3.26(9.14-11.64)$ & \\
\hline \multicolumn{5}{|l|}{ Residential area } \\
\hline Other & $126(78.8)$ & $153(68.9)$ & 1.00 (Ref) & 0.034 \\
\hline Pietermaritzburg metropolitan & $34(21.3)$ & $69(31.1)$ & $1.67(1.04-2.68)$ & \\
\hline \multicolumn{5}{|l|}{ Referral centre } \\
\hline District & $50(32.7)$ & $68(31.6)$ & 1.00 (Ref) & 0.865 \\
\hline Regional & $100(65.4)$ & $141(65.6)$ & $1.04(0.66-1.62)$ & \\
\hline $\begin{array}{l}\text { Tertiary outside drainage area + } \\
\text { private }\end{array}$ & $3(2.0)$ & $6(2.8)$ & $1.47(0.35-6.16)$ & \\
\hline \multicolumn{5}{|l|}{ Smoker } \\
\hline Present or past & $81(53.3)$ & $96(46.6)$ & 1.00 (Ref) & 0.211 \\
\hline Never & $71(46.7)$ & $110(53.4)$ & $1.19(0.86-1.99)$ & \\
\hline \multicolumn{5}{|l|}{ Alcohol } \\
\hline Present or past & 78 (51.3) & $92(44.9)$ & 1.00 (Ref) & 0.229 \\
\hline Never & $74(48.7)$ & $113(55.1)$ & $1.29(0.85-1.97)$ & \\
\hline \multicolumn{5}{|l|}{ Traditional beer use } \\
\hline Present or past & $65(43)$ & $79(38.5)$ & 1.00 (Ref) & 0.392 \\
\hline Never & $86(57)$ & $126(61.5)$ & $1.21(0.79-1.85)$ & \\
\hline
\end{tabular}




\section{Body Mass Index (BMI)}

Underweight

Not underweight

HIV status

Negative

Positive

\section{Albumin}

$<30 \mathrm{~g} / \mathrm{L}$

$\geq 30 \mathrm{~g} / \mathrm{L}$

Albumin

$<25 \mathrm{~g} / \mathrm{L}$

$\geq 25 \mathrm{~g} / \mathrm{L}$

\section{Dysphagia Grade (At Presentation)}

0-1

2-4

\section{Tumour location from incisors}

Proximal oesophagus

Mid oesophagus

Distal oesophagus

Tumour length

$<8 \mathrm{~cm}$

$\geq 8 \mathrm{~cm}$

\section{Histology of the tumour}

Well-differentiated

Moderately differentiated

Poorly differentiated

${ }^{\text {an }}$ ECOG
$82(60.3)$

54 (39.7)

97 (74.6)

$33(25.4)$

$93(60.4)$

$61(39.6)$

$43(27.9)$

$111(72.1)$

24 (16.4)

$133(83.6)$
90 (41.9)

1.00 (Ref)

$125(58.1)$

$2.11(1.36-3.267)$

$<0.001$

0.976

140 (74.5) 1.00 (Ref)

$48(25.5) \quad 1.01(0.60-1.68)$

52 (26.3) $\quad 1.00$ (Ref)

$<0.001$

146 (73.7) $\quad 3.46(2.10-5.68)$

14 (7.1) $\quad 1.00$ (Ref)

$<0.001$

$184(92.9) \quad 5.09(2.66-9.73)$

57 (25.6) $1.76(1.05-2.95)$

0.033

$166(74.4) \quad 1.00$ (Ref)

\begin{tabular}{llll}
$32(20.6)$ & $39(18.1)$ & $1.00($ Ref $)$ & 0.591 \\
\hline $88(56.8)$ & $118(54.9)$ & $1.10(0.64-1.89)$ & \\
\hline $35(22.6)$ & $58(27)$ & $1.36(0.73-2.55)$ &
\end{tabular}

$86(53.8)$

$139(62.6)$

$1.44(0.95-2.18)$

0.083

$74(46.3)$

83 (37.4)

1.00 (Ref)

$\begin{array}{lllll}0-1 & 34(21.9) & 109(50.2) & 3.59(2.26-5.71) & <0.001 \\ 2-4 & 121(78.1) & 108(49.8) & 1.00(\text { Ref })\end{array}$


Abbreviation: an ECOG (Eastern Cooperative Oncology Group), OR (Odds ratio), $\mathrm{Cl}$ (Confidence interval). Variables significant at $P$ value $<0.05$ are shown in boldface.

In our multivariate model adjusting for the age at diagnosis, patients residing in the Pietermaritzburg area (aOR:1.87, 95\% Cl 1.05-3.33), not underweight (aOR: 1.72, 95\% Cl 1.05-2.84), with serum albumin $\geq 25 \mathrm{~g} / \mathrm{L}$ (aOR: 2.97, 95\% Cl: 1.42-6.20), and ECOG 0-1 (aOR: 2.68, 95\% Cl: 1.59-4.50) were more likely to survive for more than three months with OSCC (Table 4).

\section{Table 4}

\section{Multivariate analysis of factors associated with survival time $>3$ months}

\begin{tabular}{|c|c|c|}
\hline \multirow[t]{2}{*}{ Characteristics } & \multicolumn{2}{|c|}{ Multivariate analysis } \\
\hline & OR $(95 \% \mathrm{Cl})$ & P-value \\
\hline \multicolumn{3}{|l|}{ Residential area } \\
\hline Outside metropolitan area & 1.00 (Ref) & 0.033 \\
\hline Pietermaritzburg metropolitan & $1.87(1.05-3.33)$ & \\
\hline \multicolumn{3}{|l|}{ BMI } \\
\hline Underweight & 1.00 (Ref) & 0.030 \\
\hline Not underweight & $1.73(1.05-2.84)$ & \\
\hline \multicolumn{3}{|l|}{ Albumin } \\
\hline$<25 \mathrm{~g} / \mathrm{L}$ & 1.00 (Ref) & 0.004 \\
\hline$\geq 25 \mathrm{~g} / \mathrm{L}$ & $2.97(1.42-6.20)$ & \\
\hline \multicolumn{3}{|l|}{ an ECOG } \\
\hline $0-1$ & $2.68(1.59-4.50)$ & $<0.001$ \\
\hline $2-4$ & 1.00 (Ref) & \\
\hline
\end{tabular}

\section{Discussion}

The focus of research on prognostic factors in oesophageal cancer has been on factors affecting survival after curative treatment with many studies including both adenocarcinoma and squamous cell carcinoma subtypes in their analyses. ${ }^{[25,26]}$ The studies analysing factors in patients with oesophageal squamous cell carcinoma (OSCC) only are mainly from Europe or Asia, with very little data available from 
Africa. ${ }^{[27]}$ One of the few studies from Africa retrospectively reviewed prognostic factors in more than a thousand patients presenting to a single institution over 30 years and found performance status, race, weight loss and prior TB to be the strongest predictors of survival. ${ }^{[28]}$ However, most patients in this study were managed before modern diagnostic and treatment modalities for oesophageal cancer were established.

Our study was based on prospectively collected data from patients with OSCC seen at the same institution where modern palliative management modalities like self-expanding metal stents are readily available.

The variables that affected survival on multivariate analysis in our patients were body mass index, serum albumin, performance status and demographic area where the patient lives. These variables are straightforward to obtain, can be available on the day of the first presentation to the hospital and have minimal costs. By using these variables, a decision can be made on the optimal management algorithm for patients. For those with a short life expectancy, definitive palliative management can be given, e.g. stent insertion. The patient can then be followed up clinically as needed. Further investigations like staging CT scans and other special investigations can be performed before deciding on the optimal treatment for those with a longer life expectancy.

The low BMI in our study cohort is related to the inverse relationship between baseline BMI and oesophageal cancer-related mortality. ${ }^{[29]} \mathrm{BMI}$ was shown to be an independent prognostic factor in patients with OSCC, irrespective of the treatment received but data from Africa is lacking. ${ }^{[11]}$ This study underscores the significance of the negative impact of low BMI on prognosis in patients with OSCC in an African setting.

The effect of hypoalbuminaemia on survival is well documented in several clinical scenarios, albeit not fully understood. ${ }^{[30]} \mathrm{A}$ recent meta-analysis demonstrated that patients with most gastrointestinal tract cancers have improved survival with higher serum albumin levels. ${ }^{[11]}$ Most studies, however, differentiated between patients with normal serum albumin and hypoalbuminaemia and focused on patients receiving curative treatment. In our study, investigating patients receiving palliative treatment only, we used serum albumin of $25 \mathrm{~g} / \mathrm{L}$ as a cut-off value because such a large number of our patients $(69 \%)$ were hypoalbuminaemic. A previous study showed that $70 \%$ of patients are hypoalbuminaemic on presentation, making normal serum albumin less useful as a cut-off value when differentiating between patients with different prognoses. ${ }^{[32]}$ We thought it would be more helpful to differentiate between patients with severe hypoalbuminaemia (Albumin $<25 \mathrm{~g} / \mathrm{L}$ ) and those with an albumin level of at least 25g/L. [23]

Performance status has been shown to be an independent predictor of survival in oesophageal cancer. ${ }^{[33]}$ As in other centres, the poor performance status of our patients at the time of diagnosis often precludes curative treatment and, in some cases, more radical palliative modalities like chemotherapy and external beam radiotherapy. ${ }^{[34]}$ For these reasons, these patients are best managed by offering them 
appropriate definitive palliative management without subjecting them to unnecessary investigations and repeated hospital visits.

The effect of geographic area on survival may be due to many factors, including medical resources, socioeconomic disparities and geographical differences in tumour biology. ${ }^{[35]}$ Geographic area was shown to affect survival in oesophageal cancer by others. ${ }^{\text {[12] }}$

In our study, survival was significantly worse in patients that resided outside the Pietermaritzburg metropolitan area. This population comes from predominantly rural areas. The difference in survival may be due to lack of access to appropriate health care and poorer socioeconomic circumstances in rural areas. ${ }^{[36]}$

The main limitation of this study was the sample size which may have affected the results of some variables on multivariate analysis. Another was the lack of follow up data on $11.7 \%$ of patients. The study's strength is that we only included squamous cell carcinoma subtypes and that all patients were eligible for palliative management only.

\section{Conclusion}

This study allows objective variables in the decision-making process when managing patients with oesophageal cancer that are eligible for palliative treatment modalities in limited resource settings. Serum albumin, BMI, performance status and area of residence all affect survival in patients treated palliatively for OSCC. These easily obtainable variables can be used to devise a reproducible clinical score that could be validated in a follow-up study. This will result in optimal, cost-effective palliative management that will translate into improved quality of life, ultimately the main objective when managing patients with this devastating disease.

\section{Declarations}

\section{Ethics approval and consent to participate}

The study was approved by the Biomedical Research Ethics Committee of the University of KwaZuluNatal (UKZN), Durban, South Africa (Certificate number BF270/15).

No individual person's data was included in the manuscript. Hence no consemt for publication was required

\section{Availability of data and materials}

The data supporting our findings are all obtainable from the corresponding author at lucienferndale@gmail.com 


\section{Competing interests}

The authors declare that they have no competing interests.

\section{Funding}

Funding for the study was obtained from the South African Medical research council. The role of the funding body will be to assist with the publication fee.

\section{Authors' contributions}

1. Lucien Ferndale - conception, acquisition and interpretation of data, drafting of article, accountable for all aspects of the work and will ensure investigation and resolution of all queries.

2. Oluwatosin A Ayeni - study design, analysis and interpretation of data, drafting of manuscript, accountable for queries related to statistical analysis.

3. Wenlong Carl Chen - conception and design, analysis and interpretation of data, drafting of article.

4. Colleen Aldous - conception and design, interpretation of data, critical revision and supervision.

\section{Acknowledgements}

The authors would like to acknowledge Dr M Govender and Dr V Nair for assistance with clinical data collection and $\mathrm{Dr} \vee$ Govindasamy for assistance with database development.

\section{References}

1. Chen M, Huang J, Zhu Z, Zhang J, Li K. Systematic review and meta-analysis of tumor biomarkers in predicting prognosis in esophageal cancer. BMC Cancer. 2013;13.

2. Corona E, Yang L, Esrailian E, Ghassemi KA, Conklin JL, May FP. Trends in Esophageal Cancer Mortality and Stage at Diagnosis by Race and Ethnicity in the United States. Cancer Causes Control [Internet]. 2021;32(8):883-94. Available from: https://doi.org/10.1007/s10552-021-01443-z

3. Deng J, Chu X, Ren Z, Wang B. Relationship between T stage and survival in distantly metastatic esophageal cancer: A STROBE-compliant study. Medicine (Baltimore). 2020;99(19):e20064.

4. Schaafsma T, Wakefield J, Hanisch R, Bray F, Schüz J, Joy EJM, et al. Africa's oesophageal cancer corridor: Geographic variations in incidence correlate with certain micronutrient deficiencies. PLoS One [Internet]. 2015;10(10):1-13. Available from: http://dx.doi.org/10.1371/journal.pone.0140107

5. Nel D, Omar M, Chinnery G, Jonas E. Disparity in oesophageal cancer management in South Africa: A comparison between two tertiary centres with special focus on the palliation of dysphagia. South African J Surg. 2019;57(2):10-5. 
6. Loots E, Sartorius B, Madiba TE, Mulder CJJ, Clarke DL. Is Clinical Research in Oesophageal Cancer in South Africa in Crisis? A Systematic Review. World J Surg. 2017;41(3):810-6.

7. Stats SA. South African Mid-year population estimates: 2016 [Internet]. Statistical release P0302. 2016. p. 1-18. Available from: https://www.statssa.gov.za/publications/P0302/P03022016.pdf

8. Caldwell RI, Gaede B, Aldous C. Description of an internal medicine outreach consultant appointment in Western Kwazulu-Natal, South Africa, 2007 to mid-2014. South African Med J. 2015;105(5):3536.

9. Grey's Hospital [Internet]. KwaZulu-Natal Department of Health. 2021 [cited 2021 Oct 6]. Available from: http://www.kznhealth.gov.za/greyshospital.htm

10. Sur RK, Levin CV, Donde B, Sharma V, Miszczyk L, Nag S. Prospective randomized trial of HDR brachytherapy as a sole modality in palliation of advanced esophageal carcinoma - An International Atomic Energy Agency study. Int J Radiat Oncol Biol Phys. 2002;53(1):127-33.

11. Gu WS, Fang WZ, Liu CY, Pan KY, Ding R, Li XH, et al. Prognostic significance of combined pretreatment body mass index (BMI) and BMI loss in patients with esophageal cancer. Cancer Manag Res. 2019;11:3029-41.

12. Chitti B, Pham A, Marcott S, Wang X, Potters L, Wernicke AG, et al. Temporal Changes in Esophageal Cancer Mortality by Geographic Region: A Population-based Analysis. Cureus. 2018;10(11).

13. Someya M, Sakata KI, Saito A, Nagakura H, Oouchi A, Hareyama M. Results of external irradiation and low-dose-rate intraluminal brachytherapy for esophageal cancer. Acta Oncol (Madr). 2002;41(1):63-8.

14. Okawa T, Kita M, Tanaka M, Ikeda M. Results of radiotherapy for inoperable locally advanced esophageal cancer. Int J Radiat Oncol Biol Phys [Internet]. 1989 Jul;17(1):49-54. Available from: http://www.ncbi.nlm.nih.gov/pubmed/2745207

15. Imura Y, Yamamoto S, Wakamatsu T, Tanaka T, Tamiya H, Sugimura K, et al. Clinical features and prognostic factors in patients with esophageal cancer with bone metastasis. Oncol Lett. 2020;19(1):717-24.

16. Chen CZ, Chen JZ, Li DR, Lin ZX, Zhou MZ, Li DS, et al. Long-term outcomes and prognostic factors for patients with esophageal cancer following radiotherapy. World J Gastroenterol. 2013;19(10):1639-44.

17. Mirinezhad SK, Somi MH, Jangjoo AG, Seyednezhad F, Dastgiri S, Mohammadzadeh M, et al. Survival rate and prognostic factors of esophageal cancer in East Azerbaijan province, North-west of Iran. Asian Pacific J Cancer Prev. 2012;13(7):3451-4.

18. WHO. Obesity: preventing and managing the global epidemic: report of a WHO consultation. WHO Tech Rep Ser. 2000;

19. Mellow MH, Pinkas H. Endoscopic laser therapy for malignancies affecting the esophagus and gastroesophageal junction. Analysis of technical and functional efficacy. Arch Intern Med [Internet]. 1985 Aug;145(8):1443-6. Available from: http://www.ncbi.nlm.nih.gov/pubmed/4026476 
20. Azam F, Latif MF, Farooq A, Tirmazy SH, Alshahrani S, Bashir S, et al. Performance Status Assessment by Using ECOG (Eastern Cooperative Oncology Group) Score for Cancer Patients by Oncology Healthcare Professionals. Case Rep Oncol. 2019;12(3):728-36.

21. Varghese TK, Hofstetter WL, Rizk NP, Low DE, Darling GE, Watson TJ, et al. The society of thoracic surgeons guidelines on the diagnosis and staging of patients with esophageal cancer. Ann Thorac Surg [Internet]. 2013;96(1):346-56. Available from: http://dx.doi.org/10.1016/j.athoracsur.2013.02.069

22. Mohan H. Textbook of Pathology. sixth. New Dehli; 2010.

23. Gatta A, Verardo A, Bolognesi M. Hypoalbuminemia. Intern Emerg Med. 2012;7(SUPPL. 3):193-9.

24. StatsSA. Provincial profile: KwaZulu-Natal [Internet]. Report No. 03-01-74 (2011). 2014 [cited 2021 Oct 6]. Available from: http://www.statssa.gov.za/publications/Report-03-01-74/Report-03-01742011.pdf

25. Markar SR, Lagergren J. Surgical and Surgeon-Related Factors Related to Long-Term Survival in Esophageal Cancer: A Review. Ann Surg Oncol [Internet]. 2020;27(3):718-23. Available from: https://doi.org/10.1245/s10434-019-07966-9

26. Trivers KF, De Roos AJ, Gammon MD, Vaughan TL, Risch HA, Olshan AF, et al. Demographic and lifestyle predictors of survival in patients with esophageal or gastric cancers. Clin Gastroenterol Hepatol. 2005;3(3):225-30.

27. Di Fiore F, Lecleire S, Rigal O, Galais MP, Soussan E Ben, David I, et al. Predictive factors of survival in patients treated with definitive chemoradiotherapy for squamous cell esophageal carcinoma. World J Gastroenterol. 2006;12(26):4185-90.

28. Dandara C, Robertson B, Dzobo K, Moodley L, Parker MI. Patient and tumour characteristics as prognostic markers for oesophageal cancer: A retrospective analysis of a cohort of patients at Groote Schuur Hospital. Eur J Cardio-thoracic Surg. 2016;49(2):629-34.

29. Smith M, Zhou M, Whitlock G, Yang G, Offer A, Hui G, et al. Esophageal cancer and body mass index: Results from a prospective study of 220,000 men in China and a meta-analysis of published studies. Int J Cancer. 2008;122(7):1604-10.

30. Gibbs J, Cull W, Henderson W, Daley J, Hur K, Khuri SF. Preoperative serum albumin level as a predictor of operative mortality and morbidity: Results from the National VA Surgical Risk Study. Arch Surg. 1999;134(1):36-42.

31. Gupta D, Lis CG. Pretreatment serum albumin as a predictor of cancer survival: A systematic review of the epidemiological literature. Nutr J. 2010;9(1):1-16.

32. Ferndale L, Sartorius B, Aldous C, Thomson SR. Oesophageal cancer in Area 2 of Kwazulu-Natal: Predictors of late presentation. South African J Surg. 2019;57(2):4-9.

33. Song T, Wan Q, Yu W, Li J, Lu S, Xie C, et al. Pretreatment nutritional risk scores and performance status are prognostic factors in esophageal cancer patients treated with definitive chemoradiotherapy. Oncotarget. 2017;8(58):98974-84. 
34. Arends J, Baracos V, Bertz H, Bozzetti F, Calder PC, Deutz NEP, et al. ESPEN expert group recommendations for action against cancer-related malnutrition. Clin Nutr [Internet]. 2017;36(5):1187-96. Available from: http://dx.doi.org/10.1016/j.clnu.2017.06.017

35. Mohebbi M, Wolfe R, Jolley D, Forbes AB, Mahmoodi M, Burton RC. The spatial distribution of esophageal and gastric cancer in Caspian region of Iran: An ecological analysis of diet and socioeconomic influences. Int J Health Geogr. 2011;10:1-13.

36. Pacella-Norman R, Urban MI, Sitas F, Carrara H, Sur R, Hale M, et al. Risk factors for oesophageal, lung, oral and laryngeal cancers in black South Africans. Br J Cancer. 2002;86(11):1751-6.

\section{Figures}

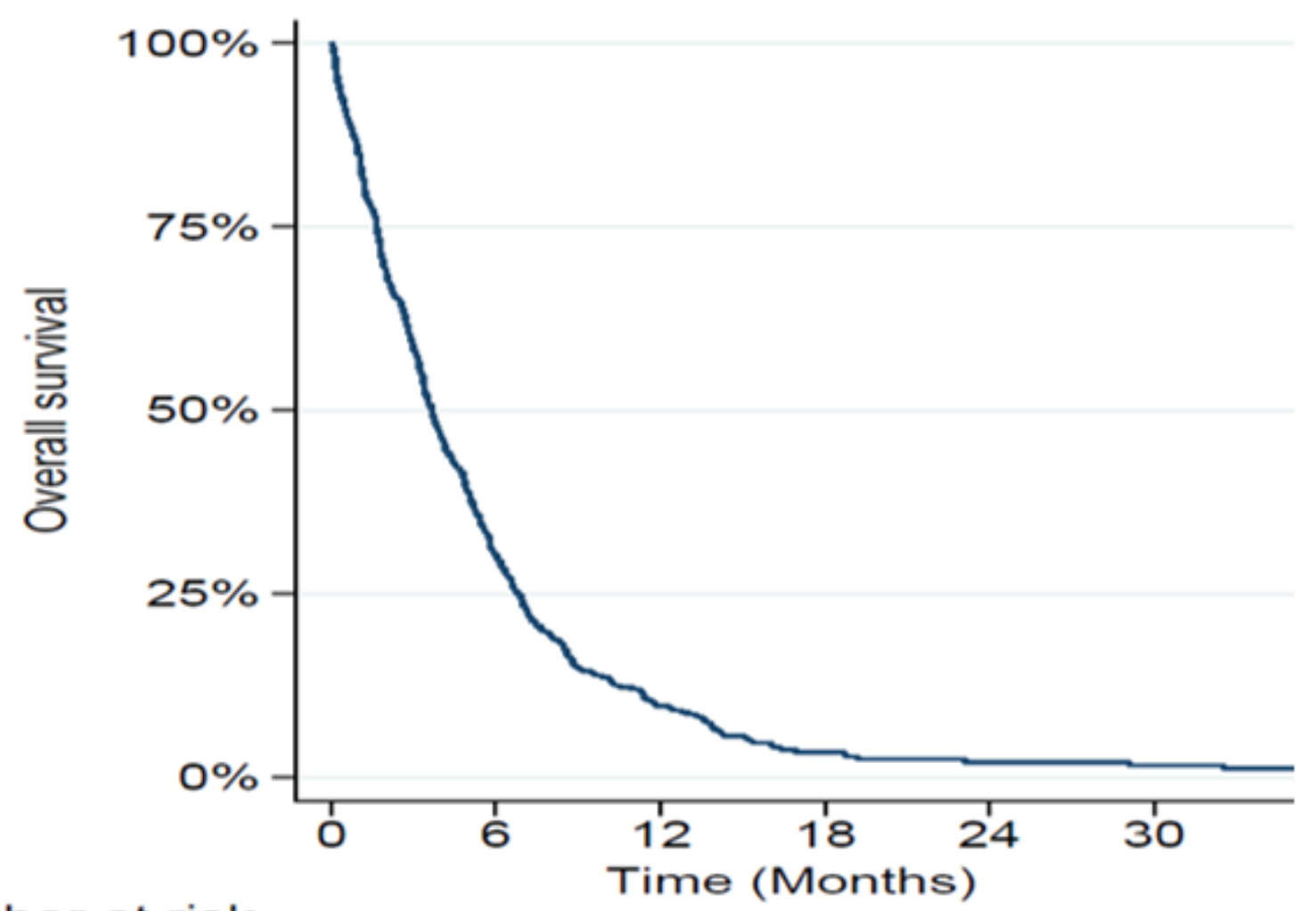

Number at risk

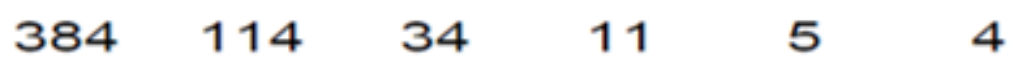

\section{Figure 1}

Kaplan-Meier survival estimate of patients diagnosed with OSCC at Grey's hospital on palliative treatment 